\title{
R-Wave Amplitude Changes During Exercise in Adolescents with Left Ventricular Pressure and Volume Overload
}

\author{
SETH WRIGHT, BS, AMNON ROSENTHAL, MD, JUDY BROMBERG, MS, and \\ ANTHONY SCHORK, PhD
}

To determine the diagnostic value of exerciseinduced R-wave changes in adolescents with congenital heart disease, the responses of 50 adolescents without significant heart disease were compared with those of 72 patients with either a left ventricular (LV) pressure or volume overload lesion. Among the pressure overload group, 24 patients had valvular aortic stenosis (AS) and 27 had coarctation of the aorta. The volume overload group included 12 patients with mitral regurgitation (MR) and 9 with aortic regurgitation (AR). Severity of the cardiac lesion was assessed using cardiac catheterization in patlents with AS, physical examination in patients with coarctation of the aorta and clinical or angiographic criteria, or both, in patients with valvular regurgitation. The $R$ wave was measured in 10 consecutive QRS complexes in leads II, aVF and $V_{5}$ at rest, maximal exerclse and 1-minute recovery. At maximal exercise, control subjects had a mean decrease in amplitude $(\Delta R)$ of $-3.6 \mathrm{~mm}$ (p
$<0.0001)$. Compared with the control group, the AS group had a similar decrease of $-3.5 \mathrm{~mm}$, but the coarctation group had a $\Delta R$ of $-1.4(p<0.005)$ and the volume overload group a $\Delta R$ of $-1.1 \mathrm{~mm}(p$ $<0.003$ ). Patients with AS and ischemic ST-segment changes during exercise $(n=12)$ had greater decreases in R-wave amplitude than did those with no ST changes $(n=12)(p<0.04)$. In patients with AS and an LV end-diastolic pressure $>12 \mathrm{~mm} \mathrm{Hg}$ ( $\mathrm{m}=$ $7)$, the decrease in $\Delta R$ was also greater than that in patients with LV end-diastolic pressure $\leq 12 \mathrm{~mm}$ $\mathrm{Hg}(n=14)(p<0.006)$. Among patients with volume overload, more severe valvular regurgitation was associated with a smaller $\Delta R(p<0.03)$. In patients with AS an increased $\Delta R$ reflects ischemia or diminished LV compliance, or both, whereas in patients with volume overload a decrease in $\Delta R$ is an indicator of the severity of regurgltation.

(Am J Cardiol 1983;52:841-846)
The determination of $\mathrm{R}$-wave amplitude changes on exercise electrocardiogram enhances the diagnostic value of the stress exercise test. A decrease in $R$-wave amplitude during exercise has been observed in adults with normal left ventricular (LV) function, ${ }^{1}$ whereas an increase or lack of change in $\mathrm{R}$-wave amplitude has been reported in patients with severe LV dysfunction or coronary artery disease. ${ }^{2,3}$ Some investigators suggest that changes in $\mathrm{R}$-wave amplitude may be more sensitive than ST-segment changes as an indicator of myocardial ischemia, ${ }^{4,5}$ but others do not confirm these

From the Division of Pediatric Cardiology, Department of Pediatrics, The University of Michigan Medical School, and The Schoot of Public Health, The University of Michigan, Ann Artor, Michigan. This study was supported in part by a grant from The University of Michigan Medical School, Ann Arbor, Michigan. Manuscript received March 21, 1983; revised manuscript received June 10, 1983, accepted June 14, 1983.

Address for reprints: Amnon Rosenthal, MD, F1123, Box 66, C.S. Mott Children's Hospital, The University of Michigan, Ann Arbor, Michigan 48109. observations. ${ }^{6-8} \mathrm{~A}$ limited number of studies have been performed on the effect of exercise on R-wave amplitude in healthy children or in children with cardiovascular disease. A decrease in $\mathrm{R}$-wave amplitude was found during exercise in normal black children. ${ }^{9} \mathrm{~A}$ smaller decrease in $\mathrm{R}$-wave amplitude was demonstrated in adolescents with systemic hypertension.10 This investigation assesses the diagnostic value of exercise-induced $\mathrm{R}$-wave amplitude changes in adolescents with cardiovascular malformations associated with LV pressure or volume overload.

\section{Methods}

Patients: Treadmill stress testing was performed in 122 adolescents aged 10 to 16 years. There were 72 study patients and 50 control subjects. Among the 72 study patients, 51 had cardiac lesions with $L V$ pressure overload and 21 had lesions associated with $L V$ volume overload. The pressure overload group included 24 patients with isolated valvular aortic stenosis (AS) and 27 patients with isolated coarctation of the aorta. The volume overload group consisted of 12 patients with isolated mitral regurgitation (MR) and 9 patients with isolated 
TABLE I R-Wave Amplitude Changes at Maximal Exercise in Adolescents with Left Ventricular Pressure and Volume Overload

\begin{tabular}{|c|c|c|c|c|}
\hline & \multirow[b]{2}{*}{$\begin{array}{l}\text { Controls } \\
(n=50)\end{array}$} & \multicolumn{2}{|c|}{ Pressure Overload } & \multirow[b]{2}{*}{$\begin{array}{l}\text { Volume Overload } \\
\qquad(n=21)\end{array}$} \\
\hline & & $\begin{array}{c}\text { Aortic } \\
\text { Stenosis } \\
(n=24)\end{array}$ & $\begin{array}{c}\text { Coarctation } \\
\text { of Aorta } \\
(n=27)\end{array}$ & \\
\hline $\begin{array}{l}\text { Age (yr) } \\
\text { Sex (M/F) } \\
\text { Resting HR (beats/min) } \\
\text { Max HR (beats/min) } \\
\text { Endurance (min) } \\
\text { Rest R-ll (mm) } \\
\text { ExerR-II (mm) } \\
\Delta R-\| l(\mathrm{~mm})\end{array}$ & $\begin{array}{c}13 \pm 2 \\
35 / 15 \\
75 \pm 16 \\
190 \pm 16 \\
15 \pm 3 \\
20.1 \pm 6.2 \\
16.5 \pm 6.7 \\
-3.6 \pm 2.9\end{array}$ & $\begin{array}{c}13 \pm 2 \\
17 / 7 \\
79 \pm 16 \\
188 \pm 17 \\
14 \pm 3 \\
24.0 \pm 8.9^{*} \\
20.5 \pm 7.7^{*} \\
-3.5 \pm 2.9\end{array}$ & $\begin{array}{c}13 \pm 2 \\
16 / 11 \\
83 \pm 14^{*} \\
187 \pm 13 \\
13 \pm 2 \\
19.4 \pm 7.0 \\
18.0 \pm 8.3 \\
-1.4 \pm 3.8^{\$}\end{array}$ & $\begin{array}{c}13 \pm 2 \\
12 / 9 \\
90 \pm 16^{\ddagger} \\
186 \pm 17 \\
13 \pm 2 \\
23.6 \pm 8.4 \\
22.5 \pm 8.5^{\S} \\
-1.1 \pm 3.8^{\ddagger}\end{array}$ \\
\hline
\end{tabular}

Values are mean \pm standard deviation.

Significance versus controls:

* $p<0.04$

$+p<0.0001$

$p<0.003$
$\mathrm{p}<<0.005$

Exer = maximal exercise; $H R=$ heart rate; $M a x=$ maximal; $R-\| l=$ height of the $R$ wave in lead $I ; ; \Delta R-\| I=$ difference between $R-I I$ at rest and maximal exercise.

aortic regurgitation (AR). Fifty adolescents with no hemodynamically significant heart disease served as control subjects. Indications for treadmill study in the control subjects included evaluation of vague chest pain, innocent murmurs or history suggestive of supraventricular tachycardia. In each, a complete history, physical examination, electrocardiogram, chest $\mathrm{x}$-ray or M-mode echocardiogram, alone or in combination, failed to disclose any significant hemodynamic or structural cardiac impairment.

Among the 24 patients with AS, 13 had no previous surgery and 11 were postoperative patients. All of the subjects with AS had cardiac catheterization within 18 months of the exercise test, with 11 of 24 having the study within the same week. In 3 of 24 patients, end-diastolic pressure was not measured before angiography. The criteria used to assess the severity of the AS were peak LV pressure, peak systolic ejection pressure gradient, LV end-diastolic pressure and ischemic ST changes during graded treadmill exercise. Severe AS was defined as a peak systolic ejection pressure gradient of $\geq 76$ $\mathrm{mm} \mathrm{Hg}$. Mean peak LV pressure for the group with AS was $150 \mathrm{~mm} \mathrm{Hg}$ (range 100 to 205) and peak systolic ejection pressure gradient was $42 \mathrm{~mm} \mathrm{Hg}$ (range 10 to 100). Seven patients with AS had LV end-diastolic pressure of $>12 \mathrm{~mm}$ $\mathrm{Hg}$, whereas 14 had pressures $\leq 12 \mathrm{~mm} \mathrm{Hg}$. No patient with AS had ST changes at rest, but 12 patients developed ST segment depression with exercise $(\geq 0.1 \mathrm{~mm})$ and 12 patients did not develop ST-segment changes.

The severity of the obstruction in the coarctation group was assessed by peak resting right-upper-extremity systolic blood pressure, maximal right-upper-extremity systolic blood pressure immediately after exercise and resting and immediate posttreadmill exercise peak systolic pressure gradient between right upper and lower extremities. Severe coarctation was defined as a resting peak systolic pressure gradient $\geq 40$ $\mathrm{mm} \mathrm{Hg}$. The mean resting upper-extremity systolic pressure in the coarctation group was $129 \mathrm{~mm} \mathrm{Hg}$ (range 104 to 150), and mean upper-extremity systolic pressure immediately after exercise was $188 \mathrm{~mm} \mathrm{Hg}$ (range 140 to 240). The mean upper-to-lower body peak systolic pressure gradient at rest was $16 \mathrm{~mm} \mathrm{Hg}$ (range 1 to 50 ) and immediate postexercise upper- to lower-body peak systolic pressure gradient was 50 $\mathrm{mm} \mathrm{Hg}$ (range 1 to 100). The hemodynamic severity of the volume overload in patients with MR and AR was graded from
1 (trivial) to 4 (severe) using previously described clinical or angiographic criteria, or both. ${ }^{11}$ Regurgitation was trivial in 5 patients, mild in 12 , moderate in 4 and severe in 1 .

Exercise testing: All subjects were exercised to exhaustion using a graded treadmill stress test according to the Bruce protocol. ${ }^{12}$ Three electrocardiographic leads (II, aVF and $\mathrm{V}_{5}$ ) were recorded continuously at speeds of 10 and $25 \mathrm{~mm} / \mathrm{s}$ at rest, during exercise and at $1,3,5$ and 10 minutes of recovery. Blood pressure readings were taken at rest, at each stage of exercise and during recovery. In addition, a lower-extremity blood pressure was obtained in patients with coarctation at rest and immediately after maximal exercise. All study patients and control subjects exercised at least 10 minutes.

R-wave analysis: Electrocardiographic tracings were analyzed using the Digisonic digitizer and computer. The height of the $R$ wave was measured in millimeters at a paper speed of $25 \mathrm{~mm} / \mathrm{s}$ using the isoelectric line as a reference. Measurements were taken from leads $I I, a V F$ and $V_{5}$ at rest, maximal exercise and 1-minute recovery. To determine the relation between the duration of exercise and $R$-wave amplitude, in a randomly selected subgroup of control subjects $(n=19)$ additional measurements were taken at each 3 -minute stage of exercise. To determine the number of QRS complexes needed to be measured to eliminate the effect of respiratory variation on the height of the $\mathrm{R}$ wave, comparison was made of consecutive measurements of 3,5 and $10 \mathrm{R}$ waves. Using an analysis of covariance no statistically significant difference in the mean $R$ wave height was observed when more than 3 complexes were measured. Nevertheless, we averaged 10 beats in each determination. The change in $R$-wave amplitude $(\Delta R)$ was defined as the difference between the average value at rest and maximal exercise or between rest and 1 -minute recovery.

Statistical analysis: Statistical analysis was performed on the Michigan Terminal System computer network using the Michigan Interactive Data Analysis System program. Values are expressed as mean \pm 1 standard deviation. Statistical tests used were the 2 -sample $t$ test and analysis of variance where indicated. The level of significance used was $p<0.05$. An increase or no significant change in the $R$-wave amplitude at maximal exercise was considered an abnormal response. This definition of an abnormal response conforms with our observations and previously published reports. ${ }^{1-5}$ Sensitivity was 
defined as the percentage of study group patients with an abnormal response, that is, true positive/true positive + false negative. Specificity was defined as the percent of control subjects with a normal test, that is, true negative/true negative + false positive. Similar directional changes in $\mathrm{R}$-wave amplitude were observed in all 3 electrocardiographic leads. The changes reported herein are those observed in lead II (R-II) except when significant additional changes were noted in other leads. Lead II was used because the tracing consistently had the most stable baseline and least artifacts.

\section{Results}

Age, sex, exercise endurance and resting and maximal heart rate of the control and study groups are shown in Table I. There was no statistical difference between control and study groups with respect to mean age, sex distribution, exercise endurance and heart rate at maximal exercise. The resting heart rate of the coarctation ( $83 \pm 14$ beats $/ \mathrm{min}$ ) and volume overload groups $(90 \pm 16$ beats $/ \mathrm{min}$ ) was significantly higher than that of the control group ( $75 \pm 12$ beats $/ \mathrm{min})$ ( $\mathrm{p}<0.04$ and $\mathrm{p}<0.0001$, respectively).

Controls: A gradual decrease in $\mathrm{R}$-wave amplitude at each successive 3-minute stage of exercise was observed in control subjects (Fig. 1). There was a mean change in $\mathrm{R}$-wave amplitude of $-3.6 \mathrm{~mm}(\mathrm{p}<0.0001)$ at maximal exercise (Table I). Among the 50 control subjects, $44(88 \%)$ had a decrease in amplitude, whereas $3(6 \%)$ showed no change and $3(6 \%)$ had an increase. There were no statistically significant differences in $R$-wave amplitude changes between male and female patients or between adolescents 10 to 12 years of age and those 13 to 16 years of age.

Aortic stenosis: Pre- and postoperative patients with AS did not differ significantly from each other in the severity of obstruction or in $\mathrm{R}$-wave response to exercise and were thus grouped together. As expected, the R-II height was significantly higher at rest in patients with

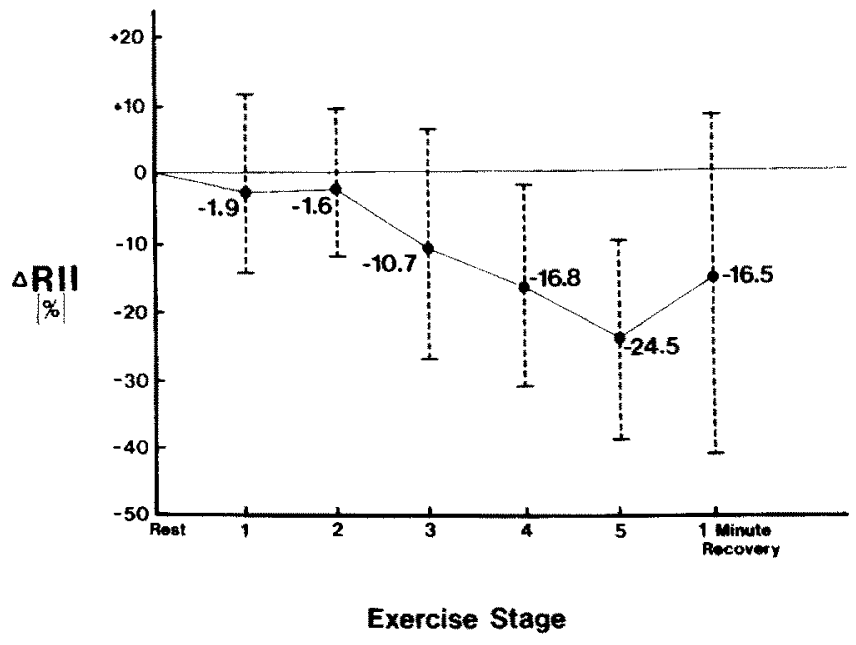

FICURE 1. Progressive decrease in R-wave amplitude during exercise in adolescents without significant heart disease, depicted as a percent change in $R$-wave amplitude in lead $\|(\Delta R \|)$ from control value at successive 3-minute stages of exercise and 1-minute recovery. Values are mean \pm standard deviation.
AS than in control subjects ( $24.0 \pm 8.9$ versus $20.1 \pm 6.2$ $\mathrm{mm})(\mathrm{p}<0.04)$. The $\mathrm{R}-\mathrm{II}$ at exercise remained significantly higher than that in control subjects $(20.5 \pm 7.7$ versus $16.5 \pm 6.7 \mathrm{~mm}$ ) ( $\mathrm{p}<0.04)$. Patients with AS had a $\Delta \mathrm{R}-\mathrm{II}$ of $-3.5 \mathrm{~mm}$ which was not significantly different from that of the control group (Table I). Because of the higher resting $\mathrm{R}$-II value in AS, the percent change in $R$-wave amplitude with exercise was also compared with that in the control subjects and was not signifi-

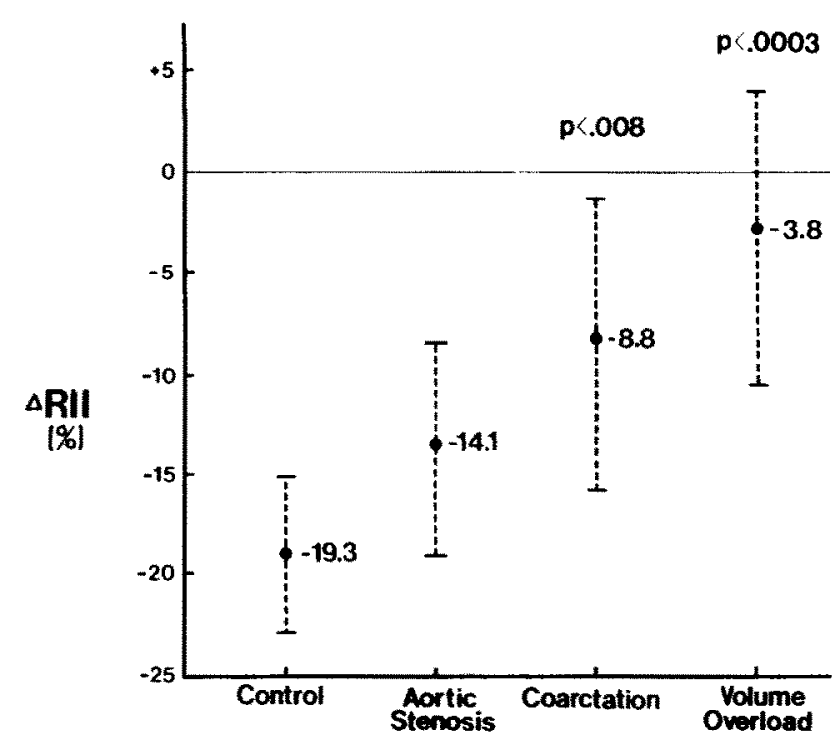

FICURE 2. Percent change in R-wave amplitude in lead II ( $\Delta R I I)$ of maximal exercise (mean \pm standard error of the mean) for control subjects and patients with aortic stenosis, coarctation and volume overioad. Patients with coarctation and volume overload have a significantly smaller decrease in R-wave amplitude.

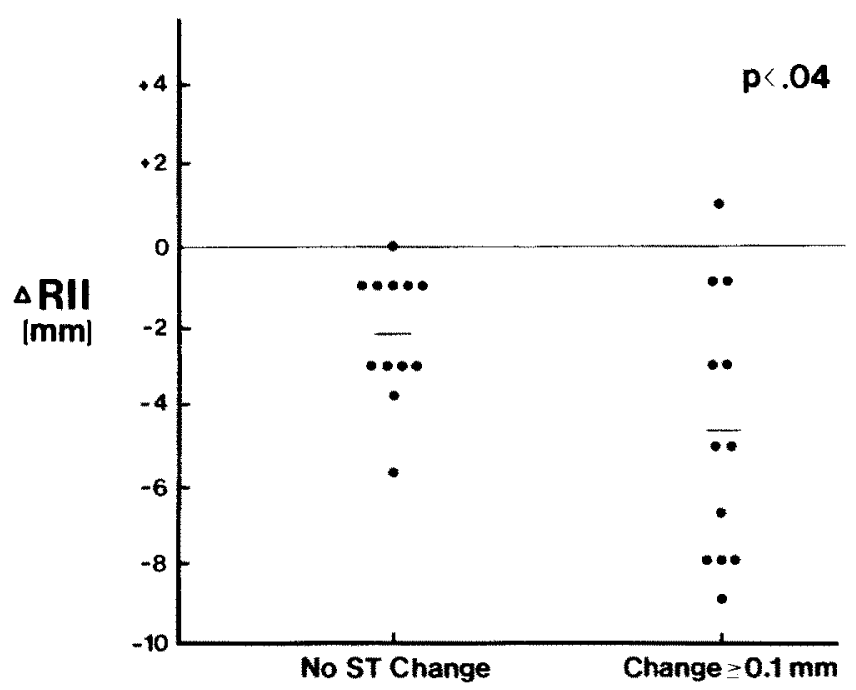

FIGURE 3. Distribution of patients with aortic stenosis according to exercise ST-segment changes. A greater decrease in R-wave amplitude ( $\triangle \mathrm{R} I 1)$ occurs in patients with aortic stenosis who develop ischemic ST changes during exercise. Although there is a great overlap in values, using a decrease in $\mathrm{R}$ of $4 \mathrm{~mm}$ or more, sensitivity is $58 \%$ and specificity $92 \%$. 
cantly different (Fig. 2). Among the 24 patients with AS, 22 patients ( $92 \%$ ) had a decrease in $\mathrm{R}$-wave amplitude, whereas $1(4 \%)$ had no change and $1(4 \%)$ had an increase in amplitude. However, patients with AS with ischemic ST changes on exercise (ST-segment depression $\geq 0.1 \mathrm{~mm})(\mathrm{n}=12)$ had a mean $\Delta \mathrm{R}-\mathrm{II}$ of $-4.8 \mathrm{~mm}$, whereas those without ischemic changes $(n=12)$ had a $\Delta$ R-II of $-2.3 \mathrm{~mm}$ ( $\mathrm{p}<0.04$ ) (Fig. 3). A large decrease in $R$ wave $(>4 \mathrm{~mm})$ at maximal exercise in patients with AS was rather specific for associated ischemic ST changes (specificity $92 \%$ ). However, a change in $\mathrm{R}$ wave was not a very sensitive measure for ischemia: $42 \%$ of patients with ST changes on exercise had only a small decrease in $\mathrm{R}$-wave amplitude $(<4 \mathrm{~mm})$. Thus, for a $\Delta \mathrm{R}$-II of $-4 \mathrm{~mm}$ or more, sensitivity was $58 \%$ and specificity $92 \%$. Patients with AS and an LV end-diastolic pressure $>12 \mathrm{~mm} \mathrm{Hg}(\mathrm{n}=7)$ had a mean $\Delta \mathrm{R}$-II of $-5.6 \mathrm{~mm}$, whereas those with an $\mathrm{LV}$ end-diastolic pressure $\leq 12 \mathrm{~mm} \mathrm{Hg}(\mathrm{n}=14)$ had a mean $\Delta R$-II of -2.1 $\mathrm{mm}(\mathrm{p}<0.006)$ (Fig. 4). For a $\Delta \mathrm{R}$-II of $-2 \mathrm{~mm}$ or more, sensitivity was $100 \%$ and specificity $64 \%$. This means that although an $R$-wave decrease $>2 \mathrm{~mm}$ is very sensitive, the decrease in the $R$ wave is not very specific, because one third the patients with normal end-diastolic pressure also had a decrease $>2 \mathrm{~mm}$. No relation could be demonstrated between peak $\mathrm{LV}$ pressure or peak systolic ejection gradient and $\mathrm{R}$-wave amplitude changes.

Coarctation: The coarctation group had a $\Delta \mathrm{R}$-II of $-1.4 \mathrm{~mm}$ which is significantly lower than that of the control group ( $p<0.005$ ) (Table I, Fig. 2). Among the coarctation group, $18(67 \%)$ patients had a decrease in $\mathrm{R}$-wave amplitude, $3(11 \%)$ showed no change, and 6 $(22 \%)$ had an increase. No correlations were observed between $\Delta \mathrm{R}$-II and resting or maximal exercise

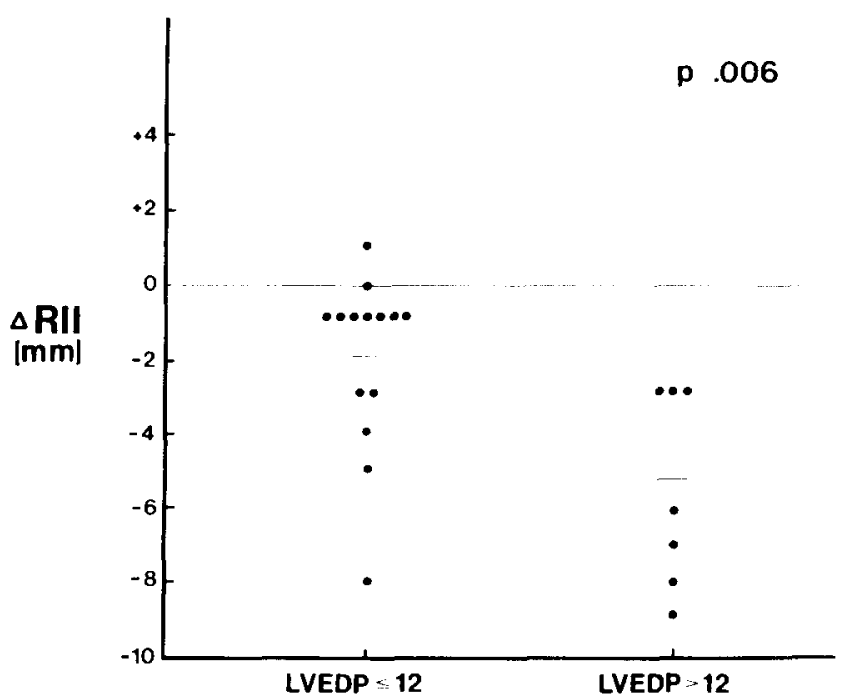

FIGURE 4. Distribution of patients with aortic stenosis according to left ventricular end-diastolic pressure (LVEDP). Patients with aortic stenosis who have an LVEDP > $12 \mathrm{~mm} \mathrm{Hg}$ tend to have a greater decrease in R-wave amplitude. Using a decrease in $\mathrm{R}$ of $2 \mathrm{~mm}$ or more, sensitivity is $100 \%$ and specificity $64 \%$. upper-extremity systolic blood pressure or resting or maximal postexercise systolic pressure gradient across the coarctation. Compared with the AS group, the LV pressure load in patients with coarctation was of lesser magnitude. However, the $\mathrm{R}$-wave response during exercise was altered to a greater degree (Fig. 2).

Volume overload: Patients with $\mathrm{MR}$ and AR had a similar response to $\mathrm{R}$-wave amplitude changes during exercise and were therefore grouped together. The $\Delta \mathrm{R}$-II of $-1.1 \mathrm{~mm}$ in patients with volume overload was significantly lower than that in the control subjects (p $<0.003$ ) (Table I, Fig. 2). Among these patients, 11 (52\%) had a decrease in $R$-wave amplitude, $2(10 \%)$ showed no change, and $8(38 \%)$ had an increase. The sensitivity for $\mathrm{R}$-II wave amplitude change with volume overload was $48 \%$ and specificity $88 \%$ (Fig. 5). Patients with more severe valvular regurgitation displayed less of a decrease in $\mathrm{R}$-wave amplitude. This finding was most striking in lead aVF when $R$-wave amplitude at rest was compared with that at 1 -minute recovery $(p<0.03$ ) (Fig. 6).

\section{Discussion}

The data indicate that children aged 10 to 16 years without hemodynamically significant heart disease respond similarly to normal adults with a progressive decrease in $\mathrm{R}$-wave amplitude during treadmill exercise (Fig. 1). These changes are observed in leads II, aVF and $\mathrm{V}_{3}$ and are significant at both maximal excrcise and 1 -minute recovery. During this age period, there appears to be no direct effect of age or sex on $\mathrm{R}$-wave response. The $\mathrm{R}$-wave amplitude response during exercise in patients with $\mathrm{LV}$ pressure and volume overload was vari-

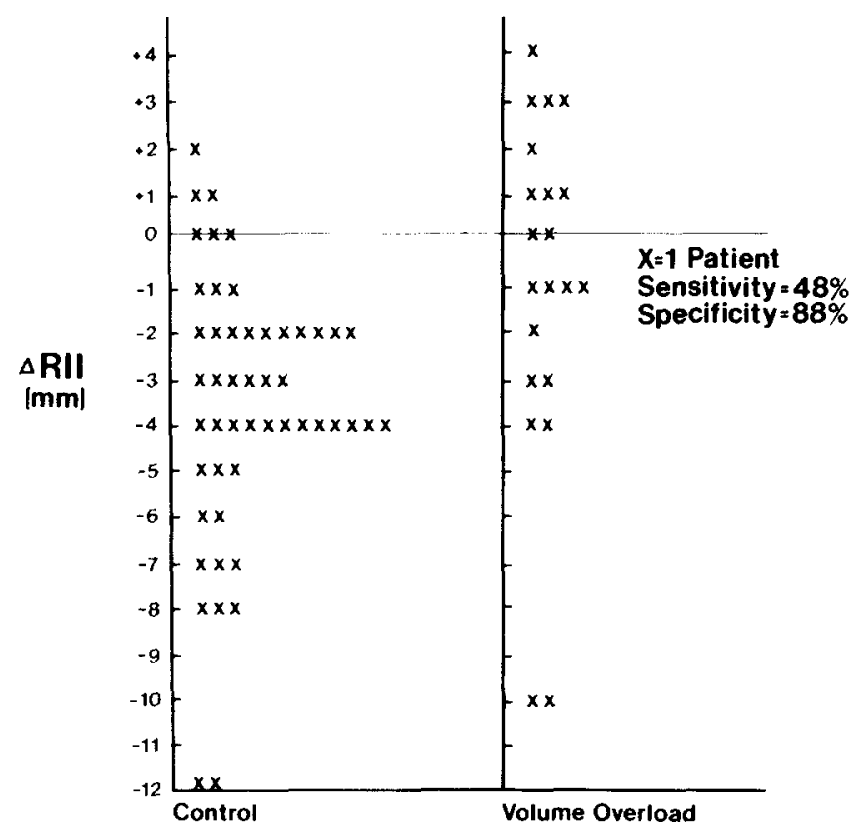

FIGURE 5. Frequency distribution of exercise-induced R-wave amplitude changes in lead II ( $\Delta R I I)$ in control subjects and patients with volume overload. Adolescents with cardiac volume overload lesions show a smaller decrease or an increase in R-wave amplitude with exerclse. 
able and dependent on the diagnostic category and in some groups on the severity of the lesion.

Change in $\mathrm{R}$-wave amplitude could not be used to distinguish patients with valvular AS from control subjects. However, within the group of patients with AS, $R$-wave amplitude changes were directly related to the severity of the disease as reflected by exercise-induced ST changes or increased LV end-diastolic pressure. Patients with AS in whom ST-segment depression developed during exercise and those with elevated resting LV end-diastolic pressure had a significantly greater decrease in $\mathrm{R}$-wave amplitude than did patients without ST-segment changes or normal LV end-diastolic pressure (Fig. 3 and 4). We could not demonstrate any correlation between changes in $R$-wave amplitude and LV peak systolic pressure or systolic ejection gradient. $\mathrm{R}$-wave amplitude changes may be related to longstanding severe LV hypertrophy, diminished ventricular compliance and subendocardial ischemia rather than to the prevailing LV peak pressure or gradient. Comparative data on adult patients with AS would be of interest but have not been examined.

In contrast to AS, the change in R-wave amplitude in patients with pressure overload due to coarctation differed from that of the control subjects in both direction and magnitude. In patients with coarctation there was a significantly smaller decrease in $R$ wave during exercise. The difference in response may be related to the absence of severe LV hypertrophy or subendocardial ischemia in patients with coarctation. A

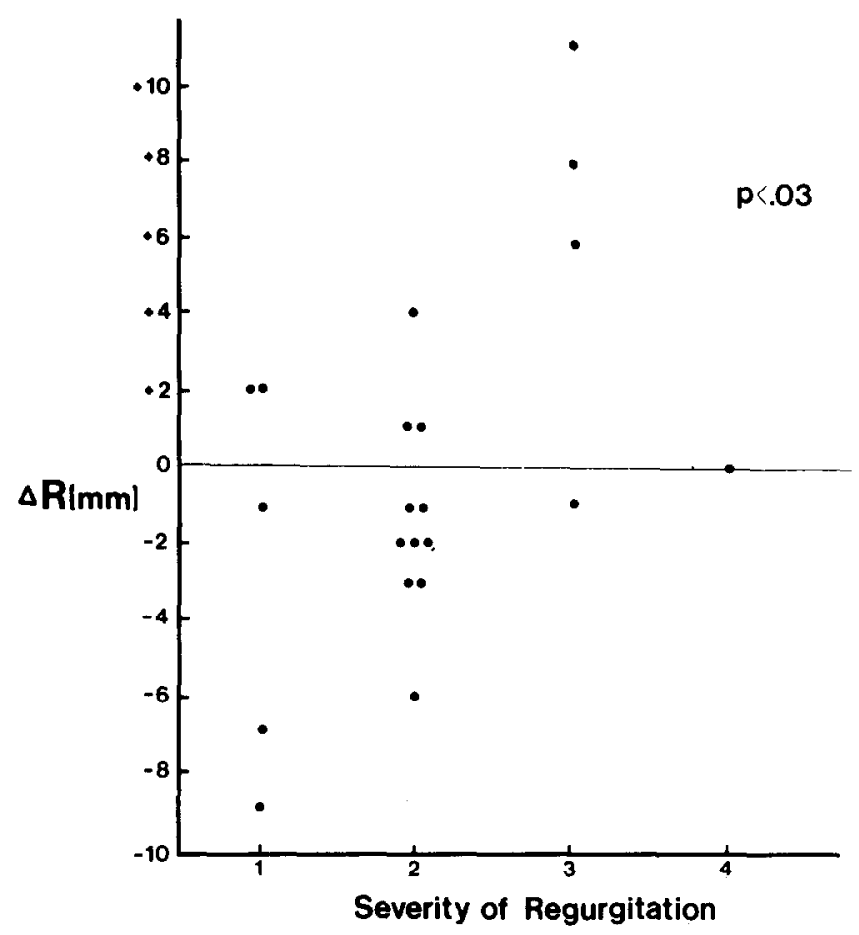

FIGURE 6. Relation between the severity of volume overload and the change in $R$-wave amplitude $(\Delta R)$ in lead aVF (resting to 1-minute recovery). Progressively greater volume overload results in increased amplitude of the $R$ wave. similar response to exercise was observed in adolescents with essential systemic hypertension. ${ }^{10}$

The group with $L V$ volume overload associated with MR or AR had a significantly smaller decrease in Rwave amplitude than did the control subjects. The change in $R$ wave was directly related to the severity of valvular regurgitation (Fig. 6 ). The changes might have been more striking if the patient population had included more patients with severe regurgitation.

The mechanism of changes in $\mathrm{R}$-wave amplitude during exercise remains controversial. According to the Brody effect, a change in the LV volume may be expected to influence the QRS voltage recorded on the surface electrocardiogram. ${ }^{13} \mathrm{~A}$ decrease in the LV end-diastolic volume in normal persons during exercise would be expected to cause a decrease in $\mathrm{R}$-wave amplitude, whereas an increase in LV end-diastolic volume, as in persons with severe $\mathrm{LV}$ dysfunction, would cause an increase in $\mathrm{R}$-wave amplitude. Several investigators, using animal models, ${ }^{14-16}$ have confirmed changes in the $R$ wave with intracardiac volume changes. The increased LV end-diastolic volume in adolescents with MR or AR and volume overload could readily explain the $\mathrm{R}$-wave changes in these patients.

More recent studies using an ischemic model or patient population with coronary artery disease demonstrate that $R$-wave amplitude changes and ventricular volumes do not always correlate. ${ }^{6,17}$ In an attempt to separate the effects of ischemia from volume changes, David et $a^{18}$ produced ischemia in dogs by coronary artery ligation and clamping the vena cava to reduce ventricular volume. An increase in $R$-wave amplitude occurred despite a decrease in volume. These findings suggest that ischemia may have an independent effect on the amplitude of the $\mathrm{R}$ wave. Further support for the role of ischemia may be obtained by examining the genesis of the precordial $R$ wave. The surface $Q R S$ complex is postulated to be a composite of the epicardial QRS and the endocardial QS. Ellestad ${ }^{19}$ observed that in patients without ischemia, the endocardial QS complex increased with increasing heart rate and that the precordial $\mathrm{R}$ wave decreased in amplitude; thus, the expected normal decrease in surface-recorded $R$ wave during exercise. Lekven et $a^{20,21}$ found that with an increase in volume in dogs the endocardial potential decreased while the epicardial potentials decreased also, but to a lesser magnitude. When ischemia was combined with LV volume overload, the endocardial potential decreased even more, whereas the epicardial potential no longer decreased. These observations suggest that changes in the endocardial and epicardial potentials during exercise could cause a change in $\mathrm{R}$-wave amplitude. It is possible that in adolescents with severe AS the development of ischemic changes results in increased endocardial QS potentials and a further decrease in $\mathrm{R}$ recorded at the surface. In contrast to that in patients with coronary artery disease, LV end-diastolic volume in these patients is normal or decreased..$^{22}$ The mechanism for an increase or smaller decrease in $\mathrm{R}$-wave amplitude during exercise in patients with coarctation may be an increased LV end-diastolic vol- 
ume and the absence of ventricular ischemia on the resting or exercise electrocardiogram.

Our findings indicate that normal adolescents exhibit $\mathrm{R}$-wave amplitude changes similar to those in normal adults, and that $R$-wave amplitude changes in adolescents with congenital heart disease depend on the type and severity of the malformation. $\mathrm{R}$-wave measurements at maximal exercise may be useful in identifying patients with AS and increased LV end-diastolic pressure and in assessing the severity and progression of disease in patients with volume overload lesions.

\section{References}

1. Keniala E, Helkklla J, Pyorala K. Variations of QRS amplitude in exercise ECG as an index predicting result of physical training in patients with coronery heart disease. Acta Med Scand 1973;194:81-86.

2. Bonorts PE, Greenterg PS, Cactellanot MW, Elledad MH. Significance of changes in $R$ wave amplitude during treadmill stress testing: angiographic correlation. Am J Cardiol 1978;41:846-851.

3. Berman JL, Wynne J, Cohn PF. Hemodynamic correlates of increased R wave sum in

4. Bonoris PE, Creenberg PS, Christison GW, Casteliant MW, Ellealad MH. Evaluation of $R$ wave amplitude changes versus ST segment depression in stress testing. Circulation 1978;57:904-910.

5. Chrtetion CW, Bonorls PE, Greenbery PS, Castellanet MJ, Ellestad MH Comparison of changes in R wave amplitude and ST segments in treadmil stress testing as a predictor of CAD (abstr). Am J Cardiol 1978;41:376.

6. Battier A, Froellcher V, Shutcky A, Achbum W. Relationship of QRS amplitude changes during exercise to left ventricular function and volumes and the diagnosis of coronary artery disease. Circulation 1979;60: and the diegn

7. Weoner $\mathbf{S}$, Cohn $K$, Selzer $H$. Unreliability of exercise induced $R$ wave changes as index of coronary artery disease. Am J Cardiol 1980;44: changes as

8. Simoons ML, Hugenholiz PQ. R wave and ST segment changes during exercise: relative values in diagnosis of coronary artery disease (abstr). Am J Cardiol 1979;43:353.

9. Thanar MX Strong WB, Mitler MD, Leatherbury L, Salehbhal M. Exercise electrocardiography of healthy black children. Am J Dis Child 1978;132: 592-595.

10. Falkner B, Lowenthal DT, Aftrime MB, Hamstra B. Changes in R wave amplitude during aerobic exercise stress testing in hypertensive adolescents. Am J Cardiol 1982; 50:152-156.

11. Losay J, Rosenthal A, Casteneda AR, Bernhard WH, Nadas A. Repair of ASD primum: results, course and prognosis. J Thorac Cardlovasc Surg 1978; 75:248-254

12. Bruce RA. Exercise testing of patients with coronary heart disease. Ann Clin Res 197 $1 ; 3: 323-332$

13. Brody DA. A theoretical analysis of intercavity blood mass influence on the heart-lead relationship. Circ Res 1956;4:731-738.

14. Manoach M, Gitter S, Groseman E, Varon D, Gasener S. Influence of hemorrhage on the QRS complex of the electrocardiogram. Am Heart J 1971;82:55-61.

15. Horen LG, Andreae RL, Yoflee HF. The effect of intracavitary carbon dioxide on surface potentials in the intact canine chest. Am Heart J 1961; 61: $504-514$.

16. Nelson CV, Chatterjee N, Angetakos ET, Hecht HH. Model studies on the effect of intracardiac blood on the electrocardiogram. Am Heart J 1961; 62:83-92.

17. Greenberg PS, Ellestad MH, Berge R. Correlation of R-wave and EF changes with upright bicycle stress testing (abstr). Circulation 1980;62: 111.

18. David D, Masahito N, Chen CC, Michotson EL, Morganroth J, Schaffenburg M. R-wave amplitude variations during acute experimental myocardial ischemia: an inadequate index for changes in intracardlac volume. Circulation 1981:63:1365-1371.

19. Ellestad MH. The mechanism of exercise-induced R-wave amplitude changes in coronary heart disease. Still controversial. Arch Intern Med changes in coronary

20. Lekven J, Chatterjee K, Tyberg JV, Stone DJ, Mathey DG, Parmley WW. Pronounced dependence of ventricular endocardial QRS potentials on ventricular volume. Br Heart J 1978;50;891-901.

21. Lekyen J, Chatterjee K, Tyberg JV, Parmley WW. Influence of left ventricular dimensions on endocardial and epicardial ORS amplitude and TT-gegment elevations during acute myocardial ischemia. Circulat 1980;61:679-688.

22. Graham TP Jr, Lewis BW, Jarmakani MM, Canent RV, Capp MP. Left heart volumes and mass quantification in children with left ventricular pressure overload. Circulation 1970;41:203-212. 